\title{
AN OVERVIEW OF STRESS ANALYSIS OF HIGH-ENERGY PIPELINE SYSTEMS USED IN THERMAL POWER PLANTS
}

\author{
Sanjay Koorse ${ }^{1}$, Malabika Roy ${ }^{2}$, M. Janardhana ${ }^{3}$, S. Seetharamu ${ }^{4}$ \\ ${ }^{I} P G$ Student, University B.D.T College of Engineering, Davangere \\ ${ }^{2} J R F$, Materials Technology Division, Central Power Research Institute, Bangalore \\ ${ }^{3}$ Materials Technology Division, Central Power Research Institute, Bangalore \\ ${ }^{4}$ Materials Technology Division, Central Power Research Institute, Bangalore
}

\begin{abstract}
A typical high-energy piping systems consists of the main steam, reheat (hot and cold) and boiler feed pump (BFP). The initial design of the system is based on elastic analysis to ensure that the stresses and deflections fall within established code limits. The important reason for analyzing the piping is that many power plants were built before (40 to 50 years) computer analysis techniques were available. The main aim of piping stress analysis is to check the design, which will allow simple and economical piping supports and provide flexibility to the piping system for thermal expansion. The piping stress analysis is carried out using CAEPIPE software. By using this software we can evaluate stresses, stress ratios, flange condition, support loads, element forces and displacements at each node. In this paper, only the maximum and minimum displacement results are tabulated.
\end{abstract}

Keywords: CAEPIPE software, High-energy pipelines, Pipe supports and Piping stresses.

\section{INTRODUCTION}

The critical components of thermal power plants undergo different types of material degradation mechanisms such as creep, thermal fatigue, corrosion, etc. during service at high pressure and temperatures environments. Main steam and hot reheat piping are considered as critical high energy piping systems in the thermal power plant. These pipelines are used for the transportation of steam in the thermal power plants and are also used in transporting fluid or air in nuclear power plants, chemical plants, petrochemical plants, refineries, etc. $[1,5]$

From the literature study, it is found that the life estimation studies mainly focused on the boilers and turbines of thermal power stations, but the piping systems and its supports are over looked. For the past few years it is recognized that the piping systems and its supports also requires equal attention. $[6,8]$

\section{CODES AND STANDARDS}

For scientific design of piping systems, selection of proper material for construction and to detail out the material specifications, knowledge of codes and standards is essential.

\subsection{Codes}

A code is basically a standard that has been generally accepted by the government. The objective of each code is to ensure public and industry safety in a particular activity or equipment. Codes are often developed by the same organizations that develop standards [2].

\subsection{Standards}

Standardization can and does, reduce cost, inconvenience and confusion that results from unnecessary and undesirable differences in systems, components and procedures. Documents prepared by a professional group who are believed to be good and proper engineering practice, the user is responsible for the correct application of the same. [2]

\subsection{Recommended Practices}

Documents prepared by professional group or committee indicating good engineering practices but which are optional. Each country has its own Codes and Standards, on global basis American National Standards are undoubtedly the most widely used and compliance with those requirements are accepted world over.

In India, other than American standards, British standards and Indian standards (BIS) are also used for design, selection of equipment and piping systems. [1,5]

\subsection{Guidelines}

Documents prepared by agencies, organizations describing engineering methods that are considered good practice but have no specific recommendation or requirement. $[1,5]$ 


\subsection{Piping Codes}

ASME B31.1 - Power Piping
ASME B31.2 - Fuel Gas Piping
ASME B31.3 - Process Piping
ASME B31.4 - Liquid Piping
ASME B31.5 - Refrigeration Piping
ASME B31.8-Gas Distribution and Transportation
ASME B31.9 - Building Service Piping

\section{FLEXIBILITY}

Piping systems should have sufficient flexibility so that piping movements or movements of supports will not cause the following:

i. Failure of piping from overstress or fatigue.

ii. Leak at joints.

iii. Detrimental loads on connecting equipment, resulting from excessive thrusts and movements imposed by piping.

iv. Failure of pipe supports.

The purpose of carrying out a piping flexibility analysis is to ensure that the above mentioned requirements are satisfied.

i. For this purpose the layout should not be too rigid.

ii. Longer piping with many bends will result- increase in the cost of materials, fabrication and installation as well as increases operating cost due to large pressure drop. [1]

The piping system shall be designed as per applicable codes and shall satisfy the following requirements of flexibility:

i. The reaction forces computed shall not be detrimental to supports, structure or connected equipment.

ii. The calculated movements of the piping shall be within desirable limits as per good engineering practice. [5]

Allowable displacement stress, $\sigma_{\mathrm{a}}=\mathrm{f}\left(1.25 \sigma_{\mathrm{c}}+0.25 \sigma_{\mathrm{h}}\right)$ as defined in ASME B31.1, code for power piping. [1,7]

Where, $\sigma_{c}=$ Basic allowable stress at minimum metal temperature expected during the displacement cycle during operation.

$\sigma_{\mathrm{h}}=$ Basic allowable stress at maximum metal temperature expected during the life time of the piping.

$\mathrm{f}=$ stress range reduction factor for cyclic conditions for total number of full temperature cycles during the life time of the plant.

The computed stress, $\sigma_{\mathrm{c}}=\sqrt{ }\left(\sigma_{\mathrm{b}}{ }^{2}+4{\sigma_{\mathrm{t}}}^{2}\right)$

Where, $\sigma_{\mathrm{b}}=$ Resultant bending stress

$\sigma_{\mathrm{t}}=$ Torsional stress $=M / 2 Z$

$\mathrm{M}=$ Torsional movement

$\mathrm{Z}=$ Section modulus of pipe
The resultant bending stress for elbows, bends and full size outlet branch connections shall be calculated as:

$$
\sigma_{\mathrm{b}}=\sqrt{ }\left[\left(\mathrm{I}_{\mathrm{i}} \mathrm{M}_{\mathrm{i}}\right)^{2}+\left(\mathrm{I}_{\mathrm{o}} \mathrm{M}_{\mathrm{o}}\right)^{2}\right] / \mathrm{Z}
$$

Where, $\mathrm{I}_{\mathrm{i}}=$ In-plane stress intensification factor

$\mathrm{I}_{\mathrm{o}}=$ Out-plane stress intensification factor

$\mathrm{M}_{\mathrm{i}}=$ In-plane bending moment

$\mathrm{M}_{\mathrm{o}}=$ Out-plane bending moment

\section{METHODOLOGY}

The piping system is modeled by using analysis software CAEPIPE. The model is developed from piping general arrangement drawings, piping isometric drawings (P\&ID), piping and valve specifications.

Once the system is accurately modeled and applying correct boundary conditions, comprehensive stress analysis calculations are made. Analysis may be desirable for different boundary conditions. [7]

\section{SYSTEM LOADS AND STRESSES}

Specifically, loads are classified as the following three types:

\subsection{Sustained Loads}

These are those loads caused by forces that are present throughout normal operation, such as pipe weight and internal pressure. $[1,5]$

\subsection{Occasional Loads}

This load is as the name implies, are those that do not occur on a regular basis but do happen during operation. [1, 5]

\subsection{Expansion Loads}

Expansion loads are the result of pipe displacements typically caused by pipe thermal expansion and terminal point displacements from thermal expansion or foundation settlement.

Apart from these loads the other loads like- Dead Weight (DW) load, pressure loads, wind loads, seismic loads (EQ), pressure relief loads, thermal expansion (Th) loads are also considered to calculate design loads for a system. [1]

Piping stresses are categorized by the following three types:

i. Primary stresses are developed by applied mechanical loads. These stresses are not self-limiting. Failure modes are plastic deformation and bursting.

ii. Secondary stresses are developed as a result of constraint of the system against displacement such as thermal expansion. Theses stresses are self-limiting and can be relieved by deformation of the system. Failure modes are plastic instability and buckling. 
iii. Peak stresses are developed locally, and they typically do not result in distortion of the system. Peak stresses form as a result of stress concentrations. Failure mode is fatigue failure from cyclic loading.

\section{PIPE/SYSTEM SUPPORTS}

CAEPIPE software provides many support types, which enable us to model available support hardware. These supports are:

\subsection{Anchor}

An anchor can be modeled as a flexible or rigid support which by default restrains the three global translations and three global rotations at the applied node. $[1,5]$

\subsection{Restraints}

A restraint is a two way rigid support which restrains the translations along the specified global direction. We can apply all a restraint in all the three directions at the same time. [1]

\subsection{Guide}

A guide is a rigid or flexible restraint which results lateral pipe movements. [1,5]

\subsection{Limit Stop}

A limit stop is a non-linear restraint. It can be oriented in any direction and a gap can be specified on both sides of the pipe. A limit stop allows free movement for the distance of the gap and then acts as a rigid or flexible restraint. A limit stop can be used to model supports for pipe racks where vertical downward movement is restricted and upward movement is not. [1]

\subsection{Rigid Support}

As the name implies, rigid supports are intended to restrict displacement of the piping. They are used at locations in which displacement is not desired or needs to be limited, taking the form of restraints, anchors, etc. Most high-energy piping systems contain one vertical rigid support located in the longest vertical run. [5]

\subsection{Cold Pull or Cold Spring}

This is used to pre-load the piping system in a cold condition to the opposite direction to the expansion so that the effects of expansion are reduced. [5]

\subsection{Constant Load Supports}

These supports use coil springs working in conjunction with a bell-crank lever to maintain the transmitted load (P) over an extended displacement range. When thermal movements greater than 2 inches are expected or stress concerns exist at equipment nozzles where low loads must be maintained, constant load supports should be used. $[1,5]$

\subsection{Variable Load Supports}

These consist of one or more coil springs encased in a can. They supply a variable supporting load as the actuator moves based on the spring formula:

$$
\mathrm{F}_{\text {Support }}=\mathrm{F}_{\text {Initial }}+\mathrm{K} \Delta
$$

Where, $\mathrm{F}_{\text {Initial }}=$ initial load on the support.

$\mathrm{K}=$ spring stiffness

$\Delta=$ actuator displacement

The variation between cold and hot load should be normally less than $25 \%$ of the hot load condition for non-critical system. If variation is more, it is common to adopt constant load hangers. However, the constant load hangers are costly in comparison to the variable spring hangers. [1]

Springs are to be provided wherever there is a vertical movement at the point of support.

\section{PIPING SOFTWARES}

Piping stress analysis is a vital part of the power plant condition assessment program. At present, there are many software for piping stress analysis, viz.-CAEPIPE, CAESARII, AUTOPLANT, PIPE PACK, check STRESS, PDMS, etc. In this paper, piping stress analysis is carried out using CAEPIPE software. The result provide displacements, stresses, loads, stress intensification factor (SIF), etc. at different node points along the pipe. $[1,7]$

One important reason for analyzing the piping by CAEPIPE software in a condition assessment program is that the highly stressed areas can be accurately determined for subsequent replication. Another important reason for analyzing the piping is that many power plants were built before computer analysis techniques were available. [7]

\section{OBJECTIVES OF STRESS ANALYSIS}

i. The calculation of the forces, moments and stresses at all the significant locations of the piping system and their influence on the thermal expansion are calculated.

ii. Flexibility analysis calculations carried out in case of pipelines subjected to restrained thermal expansion or contraction.

iii. To avoid vibration and leakage.

iv. To ensure that the stresses in the pipeline in both cold and hot conditions are within the allowable limits.

v. To check the piping configuration for safe operation from the design point of view (Pressure and Temperature)

vi. To comply with the applicable codes (IBR, ASME, etc.) 
vii. To ensure the piping is well supported and does not sag or deflect in an unsighted way under its own weight, the weight of content and thermal insulation.

viii. To ensure that the deflections, when thermal and other loads are applied do not cause interference with adjacent piping, structures and components.

\section{RESULT WITH CAEPIPE SOFTWARE}

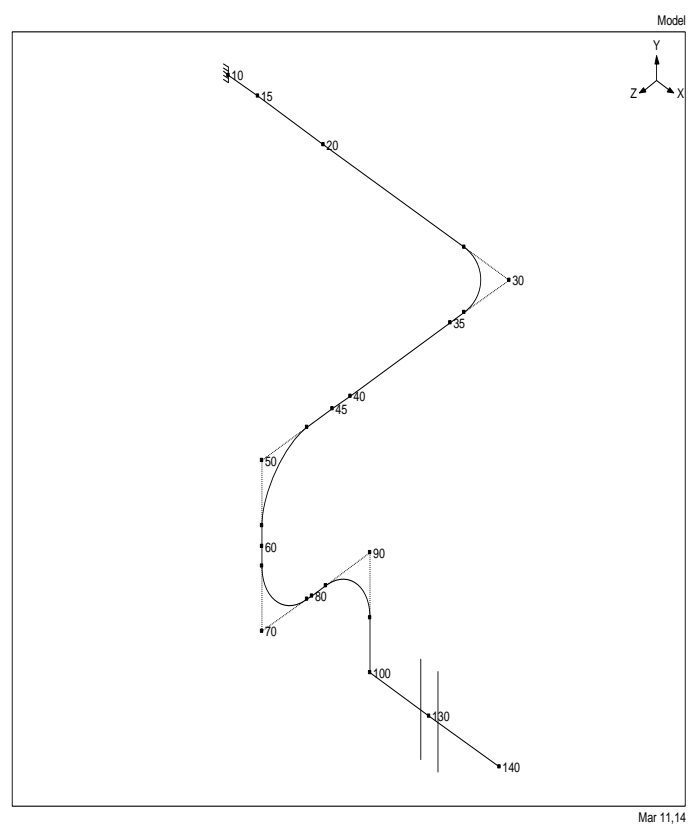

Fig-1: Piping and Isometric drawing of a High-energy pipeline.

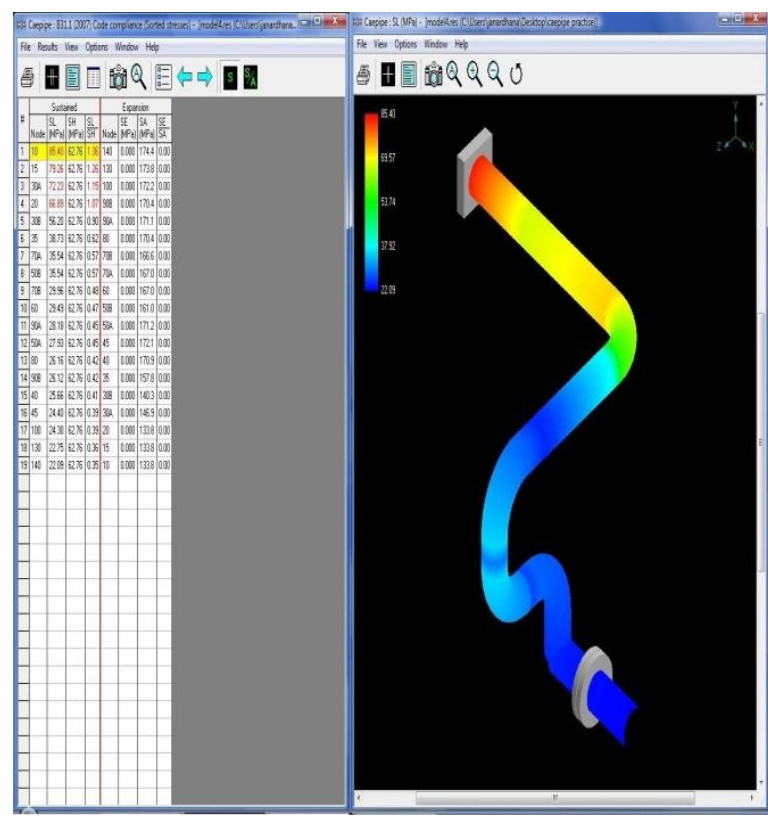

Fig-2: Stress distribution diagram after analysis.

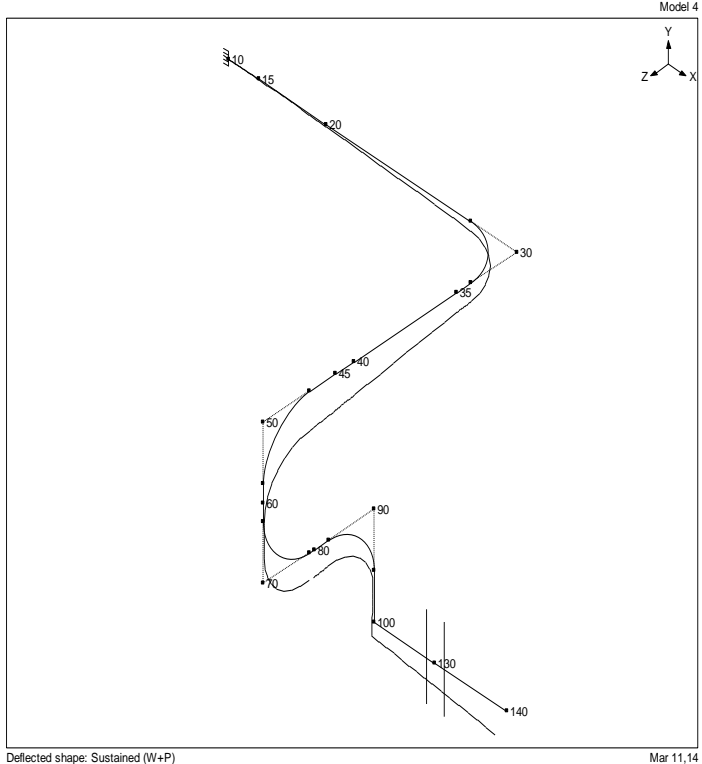

Fig-3: Displacement diagram.

Table-1: Minimum and Maximum displacement in different directions.

\begin{tabular}{|l|l|l|l|}
\hline Direction & Type & Value & Node \\
\hline $\mathrm{X}(\mathrm{mm})$ & Minimum & -7.614 & 100 \\
\cline { 2 - 4 } & Maximum & 0.000 & 10 \\
\hline \multirow{3}{*}{$\mathrm{Y}(\mathrm{mm})$} & Minimum & -16.507 & 140 \\
\cline { 2 - 4 } & Maximum & 0.000 & 10 \\
\hline \multirow{2}{*}{$(\mathrm{mm})$} & Minimum & -6.460 & 140 \\
\cline { 2 - 4 } & Maximum & 0.000 & 10 \\
\hline \multirow{2}{*}{$\mathrm{XX}(\mathrm{deg})$} & Minimum & 0.000 & 10 \\
\cline { 2 - 4 } & Maximum & 0.2941 & 45 \\
\hline \multirow{2}{*}{ YY (deg) } & Minimum & -0.0055 & $50 \mathrm{~B}$ \\
\cline { 2 - 4 } & Maximum & 0.0055 & $90 \mathrm{~B}$ \\
\hline \multirow{2}{*}{$\mathrm{ZZ} \mathrm{(deg)}$} & Minimum & -0.2759 & 140 \\
\cline { 2 - 4 } & Maximum & 0.000 & 10 \\
\hline
\end{tabular}

\section{CONCLUSIONS}

This software allows the accurate modeling of piping system which is statically indeterminate. The color diagram of stress distribution can be obtained after analysis and as per the color definition at the top left corner, the red color indicates the points of higher stresses and blue color indicates the points of lower stresses. The stress range factor shall be ideally less than one. The red zone area indicates for closer supervision during inspection.

\section{ACKNOWLEDGEMENTS}

The authors thankfully acknowledge the management of CPRI for giving permission to present this paper. 


\section{REFERENCES}

[1]. "Fossil Plant High-Energy Piping Damage: Theory and Practice", Piping fundamentals Vol.1, 2007.

[2]. T.V.V.Satyanarayana, V.Sreenivasulu, Dr.C.Udaya kiran, "Modelling and Stress Analysis of Flare Piping", International Journal of Latest Trends in Engineering and Technology.

[3]. Gaurav Bhende, Girish Tembhare, "Stress Intensification and Flexibility in Pipe Stress Analysis", International Journal of Modern Engineering Research, Vol.3, Issue 3, 2013.

[4]. Rui Liu, Zhiwei Fu, Tieping Li, "Application of pipes in Stress Analysis of Nuclear Piping", Journal of Applied Mathematics and Physics, 2013.

[5]. "A Course book on Piping Engineering", by Piping Engineering Cell, IIT, Mumbai.

[6]. Aleksandar Jakovljevic, "Stress Analysis of High Pressure Steam-lines in Thermal Power Plants".

[7] CAEPIPE User's manual by SST Systems, Inc.

[8]. ASME Pipi.ng Course. 